\title{
Aspectos histomorfométricos y cuantitativos del ovario de Patagioenas maculosa (Aves, Columbidae)
}

\author{
Histomorphometric and quantitative aspects of ovarian of Patagioenas \\ maculosa (Aves, Columbidae)
}

\section{Carina Maron, Mirian Bulfon y Noemí Bee de Speroni}

Departamento de Diversidad Biológica y Ecología, Facultad de Ciencias Exactas, Físicas y Naturales. Universidad Nacional de Córdoba. Correspondencia: Cátedra de Anatomía Comparada, Facultad de Ciencias Exactas, Físicas y exactas, Físicas y aturales, Universidad Nacional 299.Córdoba, CP. 5000. República Argentina.

Correo electrónico: Mirian Bulfon: mbulfon@com.uncor.edu

Presentado: 23/11/2011 Aceptado: $\quad 30 / 07 / 2012$ Publicado online: $01 / 10 / 2012$

\section{Resumen}

Se analizaron las variaciones estructurales y cuantitativas del ovario de Patagioenas maculosa (Temminck, 1813) durante el ciclo anual 2005 - 2006. Treinta y cinco hembras adultas se capturaron en el Departamento Río Primero (Córdoba, Argentina). Las gónadas se extrajeron, pesaron y fijaron en formol tamponado a pH 7.0 y procesaron de acuerdo a la técnica de inclusión en parafina. En la mayoría de las aves el análisis morfohistológico del ovario reveló un notorio desarrollo de la gónada desde mayo a febrero, observándose 4 ó 5 folículos vitelogénicos amarillos $\geq$ de $4 \mathrm{~mm}$ y folículos preovulatorios. El incremento del peso gonadal con un valor máximo en setiembre y octubre concordó con las características morfológicas de la fase de recrudescencia gonadal. Luego de la ovipostura, los escasos folículos en desarrollo y abundantes folículos postovulatorios y atrésicos indicaron el comienzo de la regresión ovárica. En los meses de marzo y abril, el ovario exhibió el aspecto del reposo gonadal con abundantes ovocitos primarios, folículos previtelogénicos y vitelogénicos blancos $\leq 2 \mathrm{~mm}$, escasos folículos vitelogénicos amarillos $\geq 2 \mathrm{~mm}$ y folículos atrésicos pequeños. El peso mínimo fue registrado en marzo. De los resultados se infiere que $P$. maculosa ovipone durante la mayor parte del año y que la prolongada actividad gonadal de esta ave estaría relacionada con la gran disponibilidad de alimento en el área de muestreo.

Palabras claves: Aves silvestres -ciclo reproductivo - ovario - morfohistología - análisis cuantitativo.

\section{Abstract}

Structural and quantitative variations of the ovary of Patagioenas maculosa were analyzed. Thirty five adult females were captured in Department Río Primero (Córdoba, Argentina), during the reproductive cycle from 2005 -2006. Gonads were removed, weighed and fixed in formalin buffered to $\mathrm{pH} 7.0$ and processed according to the technique of embedding in paraffin. In the most bird, the ovary morphohistological analyses revealed a marked development of the gonad from May to February with $4-5$ yellow vitelogenic follicle $\geq 4 \mathrm{~mm}$ and preovulatory follicle. The gonadal weigth increased showing the highest value in September -October,agreed with the morphological characteristic of gonadal recrudescence phase. After oviposition the few developing follicles and posovulatory follicle and abundant atretic follicle indicated the onset of ovarian regresion. In the months of March and April the ovary showed the appearance of gonadal rest with abundant primary ocytes, previtellogenic and white vitelogenic follicle $\leq 2 \mathrm{~mm}$, scarce yellow vitelogenic follicle $\geq$ and small atretic follicle The minimum gonadal weight was registres in March. The results of this study it appears that $\mathrm{C}$. maculosa egg layed during the most part of the year and the prolonged gonadal activity of this birds would be related to the greater availability to food in the study area.

Keyword: Wilds birds - reproductive cycle - ovary - structural characteristics - quantitative analysis.

\section{Introducción}

La reproducción de las aves posee características únicas entre los vertebrados, por su condición ovípara, la incubación y el cuidado de la prole. De ese modo, el estudio de los diferentes aspectos constituye un importante aporte al conocimiento de la biología reproductiva de las aves silvestres.

El análisis de las características estructurales de la gónada femenina ha sido estudiado en distintas especies por Gupta y Maití (1986), Gupta (1987a, b), Guraya (1989a, b) Bulfon y Bee de Speroni (2001, 2003, 2009), Madekuroswa (2006, 2008). Asimismo las mismas se abordaron en diferentes especies de colúmbidos como Columbina talpacoti (Ribeiro et al. 1991), Columba livia (Ribeiro et al. 1995), C. livia (Zarnesku 2004); C. maculosa. (Maron 2007), Zenaida auriculata (Bulfon 2008) y Columbina picui (Altamirano et al. 2009).

Los Columbiformes comprenden una amplia variedad de especies silvestres y domésticas que se caracterizan por su abundancia, alimentación, adaptabilidad a los diferentes hábitats (Bucher \& Ranvaud 2006), importancia sanitaria (Ito et al.
1988) y como potenciales fuentes de alimento para consumo humano (Bertonatti 1997), también por su asociación con las áreas de cultivo que utilizan para forrajeo (Saini \& Toor 1991, Marrero et al. 2004, Bucher \& Ranvaud 2006).

Varias especies de colúmbidos de zonas de clima templado están en condiciones de oviponer durante la mayor parte del año. Algunos investigadores interpretan que esta condición se debe a ciertos factores como la domesticación y la cantidad de alimento disponible (Lofts et al. 1966, Bucher 1976, Bucher et al. 1977, Yap \& Sodi 2004, Bucher \& Ranvaud 2006).

En base a estos antecedentes y teniendo en cuenta la escasa información sobre los aspectos morfológicos, en el presente estudio se realiza un estudio cuantitativo e histomorfométrico del ovario de Patagioenas maculosa (Temminck 1813) a fin de aportar conocimientos básicos sobre la reproducción de esta ave.

La Paloma manchada ( $P$. maculosa) posee una dieta principalmente granívora y en las últimas décadas, sus poblaciones se han multiplicado en la Argentina debido al auge de la agricultura que ha permitido incrementar la disponibilidad de semillas a 


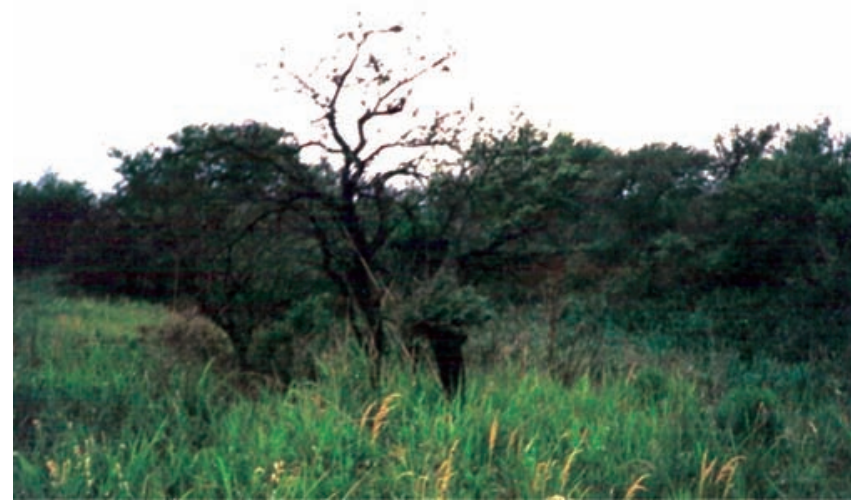

Figura 1. Vista del área de estudio. Departamento Río Primero, Provincia de Córdoba, República Argentina.

lo largo del año (Bucher 1976, Bucher et al. 1977). Asimismo, esta especie debido a su marcada preferencia por las semillas cultivadas (soja, maíz, girasol, sorgo, etc.) es considerada un ave perjudicial para la agricultura al igual que Myiopsitta monachus y Zenaida auriculata (Pergolani de Costa 1961, Bucher et al.1977, Canavelli et al. 2006).

\section{Material y métodos}

Ejemplares.- Un total de treinta y cinco hembras adultas de Patagioenas maculosa (Temminck, 1813), se capturaron con redes de niebla en el Departamento Río Primero (Provincia

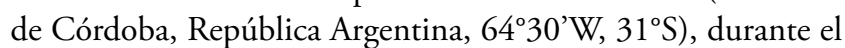
ciclo reproductivo 2005-2006. En el laboratorio, las aves, se anestesiaron y perfundieron intra cardíacamente con formalina neutra $4 \%$, luego se disecaron. Luego se removieron y pesaron las gónadas con una balanza de precisión $(0,1 \mathrm{mg})$. La ausencia de la Bursa de Fabricius, observada bajo microscopio estereoscópico $(0,7 \mathrm{X})$, se utilizó como indicador del estado adulto de las aves (Wight 1959). En campo las aves se fotografiaron con una cámara digital Sony H5 7.2 MP y en el laboratorio se utilizó un trinocular adaptado a una cámara digital Nikon Coolpix 950.

Histología.- Treinta muestras de ovario se postfijaron en formol tamponado $\mathrm{pH}$ 7,0 y procesaron de acuerdo a la técnica de inclusión en parafina. Los cortes seriados de $6 \mu \mathrm{m}$ de espesor se colorearon con hematoxilina - eosina y tricrómico de Mallory (Romeis 1928). Los folículos atrésicos se distinguieron de los folículos normales y postovulatorios de acuerdo al criterio empleado por Bulfon y Bee de Speroni, (2001, 2003). Las imágenes de las secciones de microscopía óptica fueron captadas con una cámara digital Nikkon Sight DS -Fil acoplada a un microscopio Nikkon Eclipse 50i.

Histomorfometría.- En cada estadio del ciclo (reposo, recrudescencia y regresión) fueron utilizadas 10 gónadas. De cada una se extrajeron 10 secciones histológicas mediales y se midieron y contaron todos los folículos ováricos en desarrollo (FD) y atrésicos (FA). Para este fin se empleó ImageJ 1.33 (http: //rsb.info.nih.gov/ij/Java1.5.0-rc). En las lecturas se consideró un intervalo de 80 secciones histológicas.

Análisis estadístico.- Los porcentajes de los folículos en desarrollo y folículos atrésicos se estimaron en base al promedio de lecturas realizadas en cada ovario durante la recrudescencia gonadal. Los datos se analizaron y compararon estadísticamente a través del análisis de la varianza (ANAVA). Para estudiar los

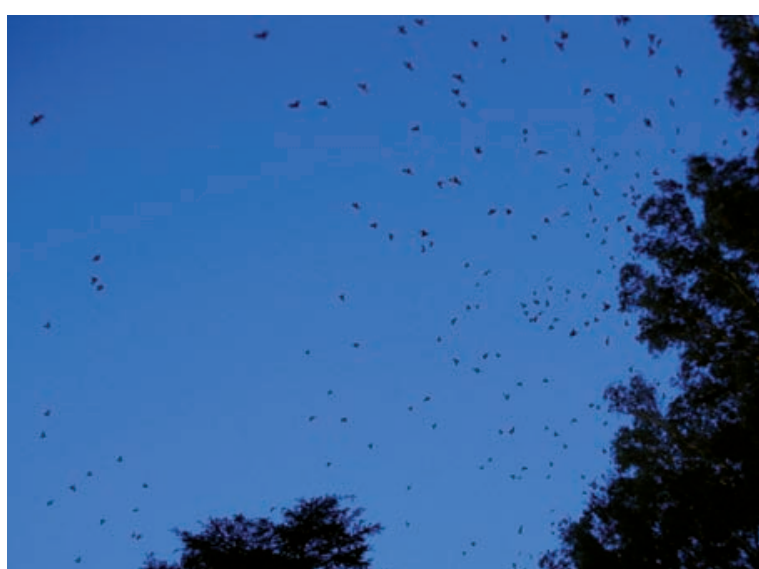

Figura 2. Nutrida bandada de Patagioenas maculosa rumbo a los dormideros al atardecer.

diferencias entre grupos se utilizó el test de Tukey. Un valor de $\mathrm{p}<0,05$ fue considerado significativo (Programa Infostat 2002).

\section{Resultados}

Características generales de la población estudiada.- La población de $P$. maculosa es muy abundante en las proximidades de la localidad de Río Primero. En esta área de estudio se localizan escasos fragmentos de la provincia fitogeográfica del Espinal con pastizales y especies como Celtis tala "tala", Acacia caven "espinillo", Aspidosperma quebracho-blanco "quebracho blanco" y Geoffroea decorticans "chañar". Este paisaje de monte se alterna con sectores cultivados que favorecen las condiciones para el desarrollo poblacional de esta especie (Fig. 1).

Durante el día, las aves realizan diferentes rutinas y la búsqueda de alimento en los campos cultivados y zonas aledańas mientras que, al atardecer se observan nutridas bandadas rumbo a los dormideros (Fig. 2).

Se observan numerosos nidos de Paloma manchada en árboles de gran porte como Eucalyptus sp., Prunus armeniaca "damasco" y variadas coníferas. El nido es una plataforma sencilla, elaborada con ramitas secas y en su construcción participa la pareja. La hembra realiza varias posturas al ańo, el huevo es blanco y de cáscara lisa con un tamaño aproximado de 38,3 x 27,3 mm (Fig. 3). En esta especie no se evidencia el dimorfismo sexual.

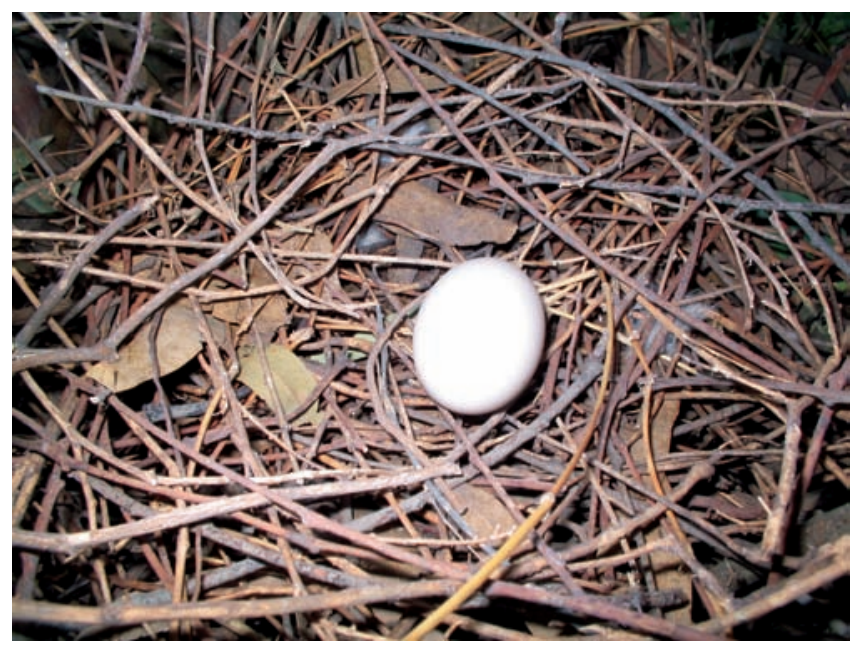

Figura 3. Nido de Patagioenas maculosa con un huevo, construido en una rama de Eucalyptus sp.a $2 \mathrm{~m}$. de altura. 


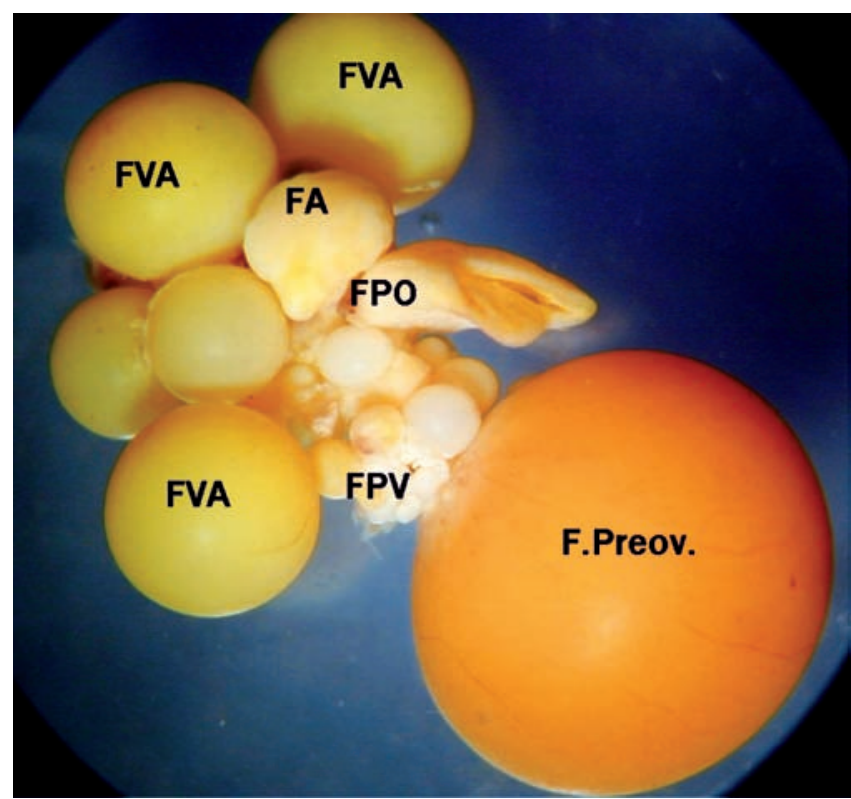

Figura 4. Vista general del ovario de Patagioenas maculosa (Recrudescencia gonadal). Se observan numerosos folículos vitelogénicos blancos (FVB) y amarillos (FVA), preovulatorio (FPOV), postovulatorio (FPO) y atrésico (FA). En la zona central del ovario se destacan numerosos folículos previtelogénicos (FPV). Escala $32 \mathrm{~mm}$.

Morfología general del ovario en fase de recrudescencia gonadal.- El aparato genital femenino es asimétrico y está constituido por el ovario izquierdo que representa la gónada funcional y el oviducto del mismo lado. El ovario posee forma triangular en la etapa de reposo, visualizándose pequeños folículos de color blanquecino en su superficie, pero a medida que se aproxima la época reproductiva la gónada incrementa el peso y tamaño adquiriendo un aspecto arracimado por la presencia de cuatro o cinco folículos amarillos de diferentes tamaños. (Fig. 4).

\section{Características histológicas del ovario}

El examen microscópico del ovario permite diferenciar dos zonas bien definidas: una periférica la corteza ovárica y otra in-

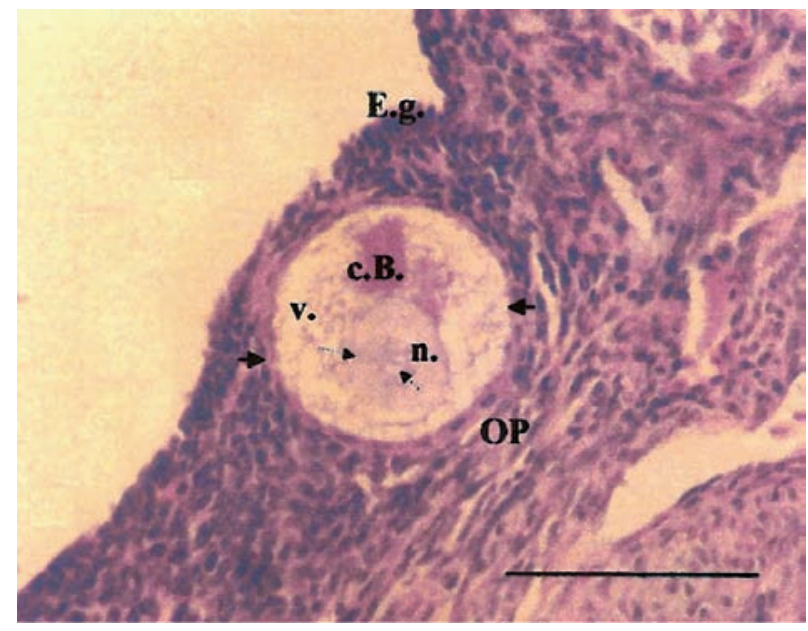

Figura 5. Ovario de Patagioenas maculosa en fase de recrudescencia gonadal. Se observa un Ovocito primordial (OP) con una capa simple de células de la granulosa (cabezas de flechas), notorio cuerpo de Balbiani (c.B), y numerosas vacuolas (v.). Las flechas indican la configuración lamp brush de los cromosomas en el núcleo (n). Las células del epitelio germinal (E.g) revisten la corteza ovárica. Hematoxilina-Eosina. Escala: $60 \mu \mathrm{m}$. terna o médula. La primera está constituida por tejido conectivo denso y una profusa red de fibras colágenas, visualizadas con la coloración Tricrómico de Mallory. En la corteza se localizan los folículos ováricos en diferentes estadios de desarrollo, los postovulatorios y los atrésicos. En la zona medular se destaca abundante tejido conectivo, denso en contacto con la corteza y más laxo con espacios lacunares hacia el interior del ovario con notorios vasos sanguíneos y nervios.

La gónada está revestida de una capa densa de células planas con núcleos basófilos denominada "epitelio germinal". (Fig. 5)

Se reconocen los siguientes tipos foliculares:

1.- Ovocitos primarios o primordiales (OP): Los OP son estructuras pequeńas $(60$ a $100 \mu \mathrm{m})$ y redondeadas, dispuestas en forma de cordones. Están constituidos por el ovocito o célula germinal y las células foliculares. El núcleo ovocitario presenta un prominente nucleolo y los cromosomas en configuración diplotene o lampbrush. Una capa de células aplanadas rodea a los OP constituyendo el estrato folicular o de la granulosa, mientras que las envolturas tecales están ausentes (Fig. 5 y 6).

2.- Folículos en desarrollo (FD): La maduración folicular está acompañada de modificaciones en el ovocito, las células foliculares y el tejido conjuntivo. A medida que los FD aumentan de tamaño, la capa simple de células granulosas originan por sucesivas mitosis un epitelio estratificado que junto a las envolturas tecales interna y externa constituyen la pared folicular. Las células de la granulosa o foliculares limitan con la capa perivitelina del ovoplasma y forman la zona radiada; están separadas de la teca interna por la lámina basal. En las envolturas tecales, con la Tinción Tricrómico de Mallory se identifican fibroblastos, fibrocitos, fibras colágenas, nervios, vasos sanguíneos, diferenciándose una teca interna con numerosos tipos celulares y una externa más colagenizada y gruesa, entre ambas se localizan células de aspecto glandular.

De acuerdo al grado de desarrollo que presentan estos folículos se categorizan en:

2a.-Folículos previtelogénicos (FPV): El diámetro de los FPV oscila entre 100 a $1000 \mu \mathrm{m}$. Las células de la granulosa forman un epitelio columnar alto pseudoestratificado

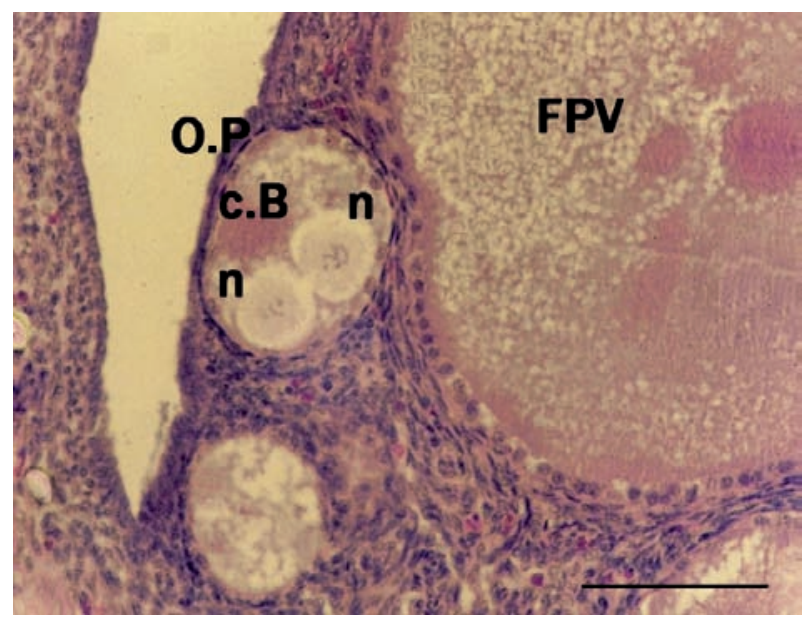

Figura 6. Ovario de Patagioenas maculosa en fase de recrudescencia gonadal. Se destaca un ovocito primordial (OP) con dos núcleos (n). En la proximidad se localiza un OP y un folículo previtelogénico (FPV). Hematoxilina-Eosina Escala: 60 um. 


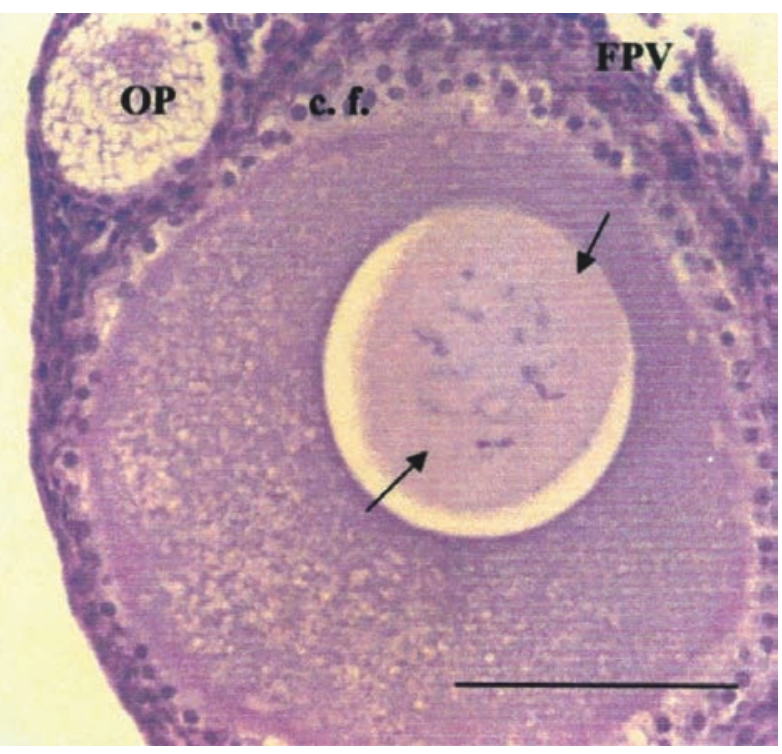

Figura 7. Ovario de Patagioenas maculosa en fase de reposo gonadal. El folículo previtelogénico (FPV) exhibe un epitelio cúbico pseudoestratificado de células foliculares (c.f.). Las flechas señalan los cromosomas en configuración lamp brush. Hematoxina-Eosina. Escala: $60 \mu \mathrm{m}$.

y las envolturas tecales están bien delimitadas. En estos folículos es notorio el cuerpo de Balbiani y las granulaciones citoplasmáticas dispuestas en la zona cortical del ovoplasma. (Fig. 7).

2b.-Folículos vitelogénicos blancos (FVB): Los folículos FVB miden entre 1000 y $2000 \mu \mathrm{m}$. Las células de la granulosa constituyen una capa pluriestratificada y las envolturas tecales están muy bien diferenciadas entre sí. En la zona cortical del ovoplasma se, evidencia la zona radiada por el aspecto estriado, también los gránulos de aspecto lipídico de variadas formas y tamaños (Fig. 8).

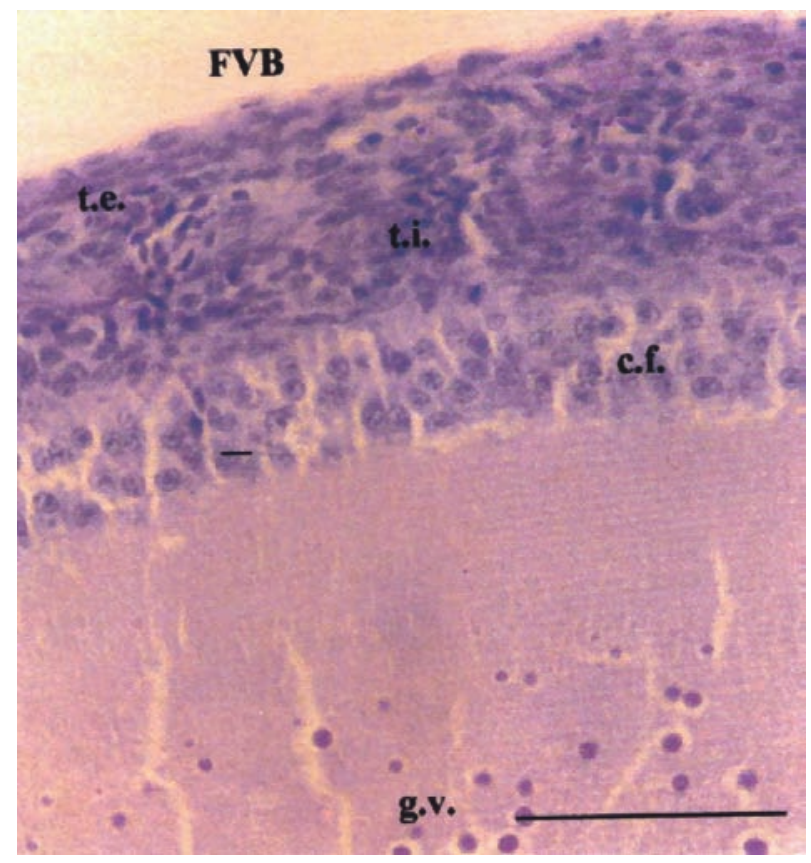

Figura 8. Ovario de Patagioenas maculosa en fase de recrudescencia gonadal. En el folículo vitelogénico blanco (FVB) se observa una capa estratificada de células foliculares (c.f.), la teca interna (t.i.) bien desarrollada y la teca externa (t.e) más conectiva. Gránulos de vitelo en el citosol. Hematoxilina-Eosina. Escala: $15 \mu \mathrm{m}$.
2c.-Folículos vitelogénicos amarillos (FVA): El cambio de color blanco a amarillo se debe a la incorporación de vitelo pigmentado. El diámetro de los FVA varía entre los $700 \mu \mathrm{m}$ y $12 \mathrm{~mm}$. Las células foliculares se comprimen y constituyen una capa de células cuboidales con núcleos muy basófilos, la teca interna se adelgaza y la externa presenta un tejido conectivo ricamente vascularizado (Fig. 9). Los cuatro o cinco FVA más grandes, constituyen un ordenamiento morfológico o de tamaño denominado jerarquía folicular. El mayor es el FVA1, sucesivamente y en orden decreciente se los denomina como FVA2, FVA3 y FVA4 (Fig. 4).

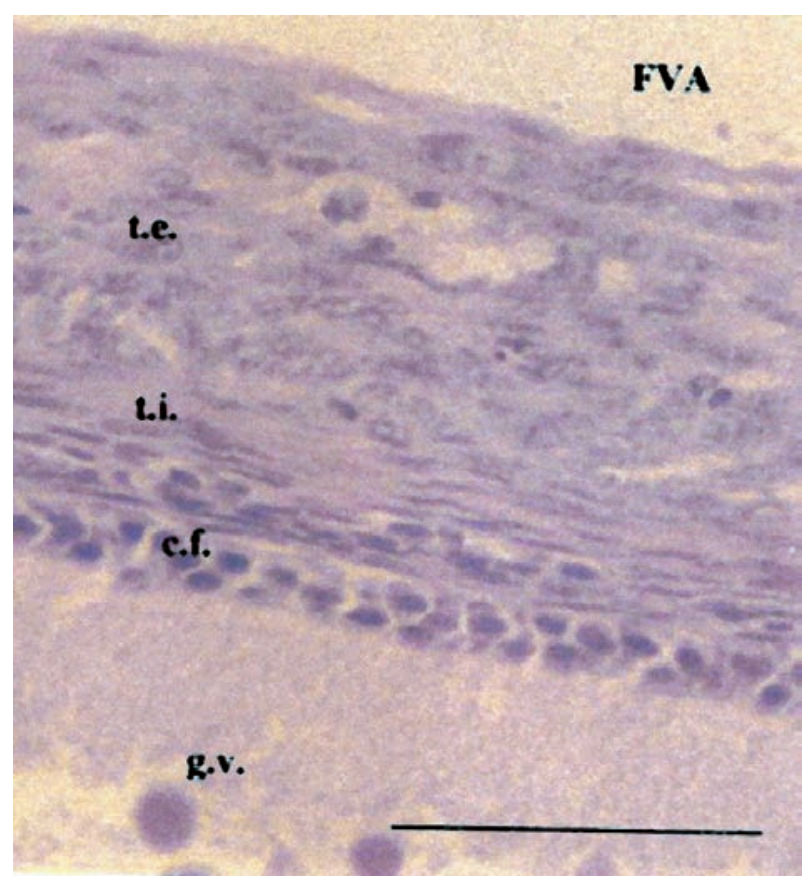

Figura 9. Ovario de Patagioenas maculosa en fase de recrudescencia gonadal. En el epitelio folicular de un folículo vitelogénico amarillo (FVA), las células foliculares (c.f.) son pequeñas y están comprimidas. La teca interna (t.i.) se diferencia de la teca externa (t.e.) que es de mayor espesor y presenta abundantes células conectivas. En el ovoplasma numerosos gránulos de vitelo (g.v.). Hematoxilina-Eosina. Escala: $15 \mu \mathrm{m}$.

2d.- Folículos preovulatorios (FPOV): Los FPOV alcanzan un diámetro entre 13 y $17 \mathrm{~mm}$ y presentan un color amarillo intenso (Fig. 4). Se observa una notable irrigación en las envolturas foliculares destacándose en el área central una zona más pálida e hipovascular denominada estigma. En esta área folicular, se produce la ruptura de las paredes foliculares durante la ovulación

2e.- Folículos postovulatorios (FPO): El diámetro de los FPO varía entre 950 y 4800 um y su aspecto macroscópico es el de un saco de tejido conectivo con una prominente abertura (Fig. 4). Con el microscopio óptico se visualizan en el interior de los mismos, restos de epitelio folicular constituido por abundantes células luteales y escasas granulosas.

3.- Folículos atrésicos (FA): La atresia folicular es un proceso degenerativo normal en el ovario y se caracteriza por la desintegración del epitelio folicular, la destrucción del núcleo o cariolisis y la fragmentación citoplasmática. Este proceso afecta a los OP, FPV, FVB y FVA y se visualiza durante todo el ciclo 


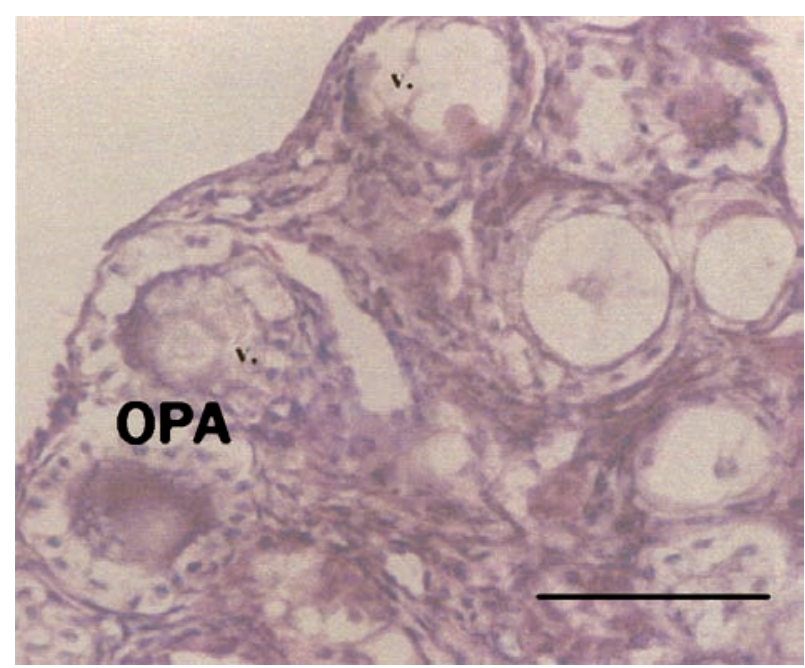

Figura 10. Ovario de Patagioenas maculosa en fase de regresión gonadal. Se observan ovocitos primordiales o atrésicos (OPA). En los folículos lipoidales se observan gran cantidad de vacuolas (v.) distribuídas en el ovoplasma y una evidente desorganización de la estructura nuclear. Hematoxilina-Eosina. Escala:60 $\mu \mathrm{m}$.

anual, siendo más notoria en la fase de regresión ovárica a posteriori de la ovipostura, durante el período de incubación y cría.

Notables cambios estructurales se detectan en los diferentes FA durante el proceso regresivo, identificándose dos tipos de atresia: a) Atresia no bursting (ANB), las paredes foliculares se mantienen intactas y el contenido ovoplásmico se absorbe in situ por las células foliculares, y b) Atresia por ruptura o bursting $(\mathrm{AB})$, las paredes foliculares se rompen y el contenido ovoplásmico se libera al exterior del folículo.

\section{3a. - Atresia no bursting. Comprende:}

3a.1.- Atresia lipoidal: Los ovocitos primordiales atrésicos (OPA) exhiben un aspecto contraído, el ovoplasma presenta gran cantidad de gotas lipídicas que paulatinamente comprimen al núcleo y las células granulosas comienzan a desprenderse de la membrana basal. Por la apariencia que ofrece el ovocito en esta etapa regresiva recibe el nombre de lipoidal. (Fig. 10).

3a. 2.- Atresia lipoglandular: Este proceso involutivo comprende a los FPV y FVB, entre 1500 y $2000 \mu \mathrm{m}$, macroscópicamente comienzan a deformarse (Fig. 4) adquieren una tonalidad grisácea y en las envolturas foliculares, la irrigación sanguínea se incrementa notablemente. En el folículo atrésico lipoglandular (FALG), la desorganización citoplasmática del epitelio folicular, la hiperestratificación y la intensa vacuolización del ovoplasma se evidencia microscópicamente (Fig. 11). En un estadio más avanzado de involución, las envolturas tecales invaden al FA, siendo notoria la irrigación del tejido conectivo. Finalmente el FALG disminuye considerablemente su tamaño y en el parénquima ovárico toma el aspecto de una cicatriz de tejido conectivo.

3b.- Atresia bursting: La atresia bursting afecta tanto a los FVA pequeños como a otros de mayores dimensiones. Macroscópicamente los folículos atrésicos bursting (FAB), se colapsan, pierden la forma y el color al inicio del proceso regresivo.
El examen de las secciones histológicas coloreadas con Hematoxilina Eosina revela que, en los primeros estadios de involución se hipertrofia el epitelio folicular, el cual paulatinamente ocupa la cavidad folicular. En un estadio involutivo más avanzado, las tecas se colagenizan y forman un cordón de aspecto trabeculado y de tonalidad azulada, con la coloración Tricrómica de Mallory.

Luego se produce la ruptura de la pared folicular formando una apertura simple y pequeña en la superficie folicular, a través de la cual se libera el contenido del ovoplasma al exterior del folículo. Esta masa ectópica cae sobre el estroma del ovario, o en la cavidad peritoneal donde será digerida posteriormente. Finalmente la cavidad central del FAB es ocupado por células muy vacuoladas, similares a las luteales, gran cantidad de fibroblastos y fibras colágenas semejantes a las de la teca externa.

4.- Ciclo reproductivo: El análisis de las características estructurales del ovario y el de los valores porcentuales de los folículos ováricos se utilizan como criterio de selección para describir las diferentes fases reproductivas.

Durante la prolongada fase de recrudescencia gonadal extendida desde mayo a febrero se incrementa el peso del ovario $(0,79 \mathrm{~g} \pm 0,441)$. En este período predominan los FVB y FVA con una marcada jerarquía folicular y 1 ó 2 FPOV. A posteriori y en coincidencia con la incubación de los huevos, se inicia la regresión gonadal. Los aspectos más destacados consisten en una progresiva disminución del peso de la gónada $(0,408 \mathrm{~g} \pm 0,12)$ con escasos FVA y el aumento de FPO durante esta fase. La regresión del ovario continúa y en los meses de marzo y abril la mayoría de las aves de la población estudiada exhiben la gónada con las características de la fase de reposo, como el aspecto liso y blanquecino, la forma triangular y el tamaño pequeño $(0,342$ $\mathrm{g} \pm 0,151 \mathrm{~g}$ ), además se ponderan abundantes OP y FPV, escasa proporción de FVB y FVA y ausencia de FPOV.

Entre las diferentes fases del ciclo, se revela un incremento significativo para el peso del ovario y el porcentaje de los FVB,

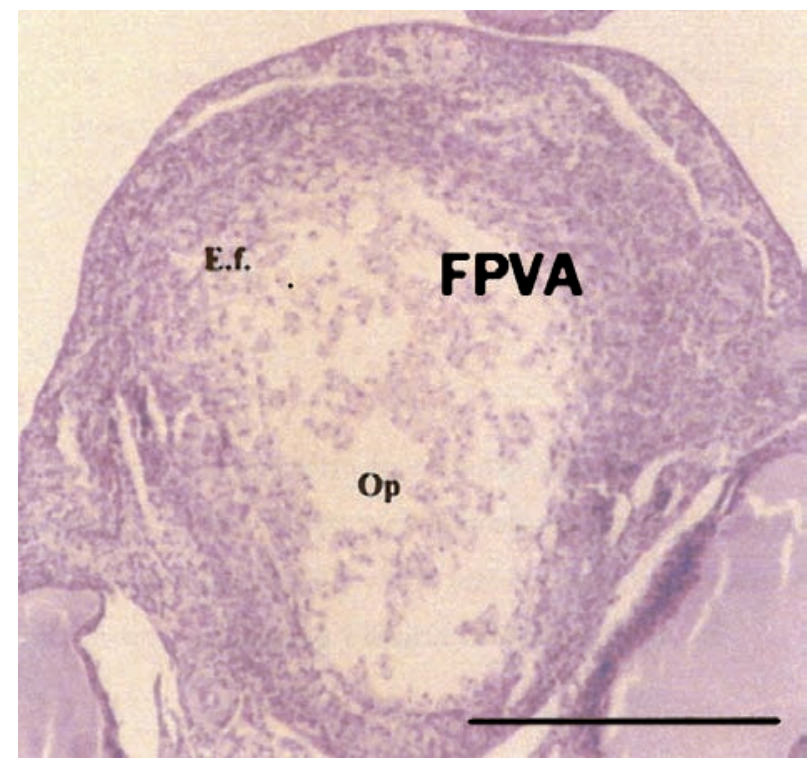

Figura 11. Ovario de Patagioenas maculosa en fase de regresión gonadal. Folículo atrésico lipoglandular (FALG). El hipertrofiado epitelio folicular (E.f.) ocupa el interior del ovoplasma (Op). HematoxilinaEosina. Escala:20 $\mu \mathrm{m}$. 
Tabla 1. Variación del peso gonadal (g) y porcentajes ((\%) de los diferentes tipos foliculares del ovario de Patagioenas maculosa entre las fases reproductivas. Los valores entre paréntesis indican el número de individuos. Los resultados representan la media y desviación estándar. Letras distintas marcan las diferencias significativas $(p<0,05)$. Referencias: Ovocitos primordiales (OP); folículos previtelogénicos (FPV), folículso vitelogénicos blancos (FVB), folículos vitelogénicos amarillos (FVA), folículos preovulatorios (FPOV), folículos postovulatorios (FPO), folículos atrésicos.

\begin{tabular}{|c|c|c|c|c|c|c|c|c|}
\hline Fase gonadal & $\begin{array}{c}\text { Peso } \\
\text { gonadal (g) }\end{array}$ & OP (\%) & FPV (\%) & FVB $(\%)$ & FVA $(\%)$ & FPOV (\%) & FPO (\%) & FA $(\%)$ \\
\hline $\begin{array}{l}\text { Recrudescencia } \\
\text { (10) }\end{array}$ & $\begin{array}{c}0,769 \pm 0,44 \\
b\end{array}$ & $\begin{array}{c}75,653 \pm 5,61 \\
a\end{array}$ & $\begin{array}{c}14,579 \pm 4,64 \\
\text { a }\end{array}$ & $\begin{array}{c}2,306 \pm 0,930 \\
b\end{array}$ & $\begin{array}{c}2,121 \pm 1,03 \\
b\end{array}$ & $\begin{array}{c}0,157 \pm 0,27 \\
b\end{array}$ & $\begin{array}{c}0,309 \pm 0,29 \\
\text { a }\end{array}$ & $\begin{array}{c}4,875 \pm 1,86 \\
\text { a }\end{array}$ \\
\hline Regresión (10) & $\begin{array}{c}0,408 \pm 0,15 \\
a\end{array}$ & $\begin{array}{c}78,046 \pm 6,59 \\
a\end{array}$ & $\begin{array}{c}16,280 \pm 4,90 \\
a\end{array}$ & $\begin{array}{c}1,538 \pm 0,851 \\
\text { a }\end{array}$ & $\begin{array}{c}0,853 \pm 0,38 \\
\text { a }\end{array}$ & $\begin{array}{c}0,000 \pm 0,00 \\
\text { a }\end{array}$ & $\begin{array}{c}0,685 \pm 0,52 \\
b\end{array}$ & $\begin{array}{c}2,598 \pm 1,78 \\
\text { a }\end{array}$ \\
\hline Reposo (10) & $\begin{array}{c}0,342 \pm 0,15 \\
a\end{array}$ & $\begin{array}{c}82,858 \pm 5,59 \\
a\end{array}$ & $\begin{array}{c}11,092 \pm 4,21 \\
a\end{array}$ & $\begin{array}{c}1,020 \pm 0,45 \\
\text { a }\end{array}$ & $\begin{array}{c}1,000 \pm 0,45 \\
\mathrm{a}\end{array}$ & $\begin{array}{c}0,000 \pm 0,00 \\
\mathrm{a}\end{array}$ & $\begin{array}{c}0,000 \pm 0,00 \\
\mathrm{a}\end{array}$ & $\begin{array}{c}4,030 \pm 1,72 \\
b\end{array}$ \\
\hline
\end{tabular}

FVA, FPOV y FA durante la recrudescencia gonadal, Por el contrario no hay diferencias significativas en los OP y FPV entre las fases analizadas (Tabla 1).

\section{Discusión}

En la población estudiada de $P$. maculosa, el análisis estructural y cuantitativo del ovario revela un ciclo reproductivo no estacional, considerando la abundancia de hembras con capacidad de reproducirse durante la mayor parte del año. Así, la extendida fase de recrudescencia gonadal desde mayo a febrero, resulta del incremento de los valores porcentuales de los FVB, FVA, FPOV y FPO, acompañado de un notorio aumento del peso gonadal. Cabe destacar, la prolongada tendencia de actividad reproductiva implica que mientras una gran cantidad de hembras están en condiciones de oviponer otras exhiben las características morfohistológicas de la gónada en fase regresiva (FVA sin jerarquía folicular, 1 a 2 FPO y numerosos FA) y realizan rutinas biológicas diferentes como la incubación, cuidado de la prole etc. Además durante este largo período también se identifica en escasos especímenes la fase de reposo gonadal (FVB, FVA $\leq 2 \mathrm{~mm}$ y FA y disminución del peso gonadal). Las características típicas del reposo gonadal son más evidentes en una gran cantidad de hembras durante los meses de Marzo y Abril.

La simultaneidad en el desarrollo de las diferente fases gonadales de $P$. maculosa concuerda con los resultados de trabajos realizados en otros colúmbidos como Zenaida macroura (Wigth, 1956), Z.auriculata (Bulfon y Bee de Speroni, 2008) y Columbina Picui (Altamirano 2009).

La abundante disponibilidad de semillas cultivadas durante todo el año en el área de estudio, favorecería el amplio ciclo reproductivo de $P$. maculosa.

Algunos autores (Lofts et al. 1966, Frithz et al.1976, Bucher 1976, Bucher et al. 1977, Rivera-Milán et al. 2003) en distintas especies de colúmbidos interpretan que, este mecanismo es el resultado de distintos factores, entre otros, la estimulación que el macho provoca en la hembra, la influencia fotoperiódica y la abundancia de alimentos.

En el ovario de $P$. maculosa, la diferenciación folicular desde ovocitos primordiales hasta la formación de los folículos preovulatorios, exhibe todas las variaciones morfohistológicas asociadas a la formación del epitelio folicular o foliculogénesis y a la deposición de gran cantidad de vitelo o vitelogénesis, ambos procesos estrechamente relacionados al crecimiento folicular.
Los aspectos estructurales del ovario de esta ave son similares a los descriptos en aves domésticas como Gallus domesticus por (Guraya 1989a), Anser anser (Kovacks et al. 1992) y silvestres como Columba livia (Guraya 1989a, b) Zarnesku 2004); Spheniscus magellanicus (Bulfon \& Bee de Speroni 2003); Struthio camelus (Madekuroswa \& Kimaro 2006, 2008); Columbina picui (Altamirano et al. 2009).

Otro mecanismo normal del ciclo ovárico de $P$. maculosa, es la atresia folicular, la cual se caracteriza por los notables cambios estructurales e histológicos en los folículos en distintos estadios de desarrollo. El significado funcional de este proceso aún no está claro, no obstante según Gupta et al. (1988), en el ovario de las especies silvestres se relaciona con la regulación de la ovulación a fin de mantener el patrón normal de ovipostura de la misma como así también evitar la puesta durante los meses en los cuales los factores ambientales no son favorables para el desarrollo de los huevos.

La atresia folicular de tipo no bursting y bursting determinados en el ovario de esta ave, también han sido descriptos en el ovario de Gallus domesticus (Gupta et al. 1988; Guraya, 1989 b) Spheniscus magellanicus (Bulfon y Bee de Speroni 2001), Myiopsitta monachus (Bulfon 2008), Vanellus chilenis e Himantopus melanurus (Bulfon \& Bee de Speroni 2009).

En conclusión, el análisis estructural y cuantitativo del ovario de $P$. maculosa revela un ciclo reproductivo no estacional, con una prolongada actividad gonadal, probablemente favorecida por la gran disponibilidad de semillas en el área estudiada. A lo largo del ciclo se desarrollan eventos asociados a la maduración y diferenciación folicular y a la regresión de los folículos no aptos. Todos estos mecanismos contribuyen a la homeostasis del ovario de este colúmbido ampliamente distribuido en la República Argentina.

\section{Agradecimientos}

Los autores agradecen a las Dras. María de los Angeles Bistoni y Andrea Hued por las sugerencias y lectura crítica del manuscrito y a la SECYT -UNC, la financiación de este trabajo, Resol. No 162/06. Una mención especial al Profesor Jorge Dongiovani por la inestimable colaboración en los trabajos a campo.

\section{Literatura citada}

Altamirano E., M. Bulfon \& N.Bee de Speroni. 2009. Histología del ovario y ciclo reproductivo de Columbina picui (Temminck,1813) (Aves: Columbidae). Rev.peru.bio.16 (1): 61-66. 
Bertonatti C. 1997. Temas de naturaleza y conservación $N^{\circ} 1$. Monografía Técnica. Buenos Aires:Asociación Ornitológica del Plata. 92 p.

Bucher E \& R. Ranvaud. 2006. Eared dove outbreaks in SouthAmerica: patterns and characteristic. Acta Zool.Sinica 52:564 -567.

Bucher E. 1976. Bases ecológicas para el control de la Paloma torcaza. Biología 1: 141 -156.

Bucher E., E. Gómez, I. Di Tada, et al. 1977. Ecología de la reproducción de la paloma Zenaida auriculata. Variaciones estacionales en peso corporal, gonadas, reservas de lípidos y muda. Ecosur 4 (7): 47 - 67.

Bulfon M. 2008. Características ultraestructurales, histoquímicas e inmunohistoquímicas de la atresia folicular de Myiopsitta monachus y Zenaida auriculata (Psittacidae y Columbidae). Tesis de Doctorado. F.C.E.F. y N. Universidad nacional de Córdoba.

Bulfon M. \& N. Bee de Speroni. 2003. Atresia folicular de Spheniscus magellanicus Forster 1871 (Aves: Spheniscidae). Ararajuba 11(2):189-194.

Bulfon M. \& N. Bee de Speroni. 2001. Efecto de la administración exógena de gonadotrofinas (FSH y LH) sobre el ovario de Myiopsitta monachus (Aves: Psittacidae). Facena 17: 67-77.

Bulfon M. \& N.Bee de Speroni. 2009. Análisis estructural e inmunohistoquímico de la atresia folicular de Vanellus chilenis e Himantopus melanurus. Rev.peru.bio. 16 (2): 169-174.

Canavelli S., M.Zaccagnini \& N. Calamari. 2006. Uso de hábitat y distribución espacial de aves potencialmente perjudiciales para cultivos en agroecosistemas pampeanos. En: Actas de la XXI Reunión Argentina de Ecología. Fronteras en Ecología: Hechos y Perspectivas. Córdoba. p. 291.

Frithz H., L. McKean \& L. Braithwaite. 1976. Sexual cycles and food of the doves Streptopelia chinensis and S. senegalensis in Australia. The Emu, 76 (1): 15-24.

Gupta S. \& B. Maití. 1986. Study of atresia in the ovary during the annual reproductive cycle of the pied myna. J. Morph. 190 (3): 285 - 296.

Gupta S. \& B. Maití. 1987 a. Ovarian activity during the annual reproductive cycle and nesting cycle of a wild avian species, the pied myna (Sturnus contra contra). Can. J. Zool. 65: 958 -966.

Gupta S. \& B. Maití. 1987 b. Influence of gonadotropins and sex hormones on the ovary of a wild avian species, the pied myna Sturnus contra contra. Arch. Biol. 98: 273 -280.

Gupta S., A. Gilbert \& A, Walker. 1988. Histological study of follicular atresia in the ovary of the domestic hen (Gallus domesticus). J.Reprod. Fert. 82: 219-225.

Guraya S. 1989 a. Ooplasmic components. Pp. 46 - 60. In: W.Burggren, S.Ishii. H. Langer, G. Neuweiler y D-Randall (eds.). Zoophysiology, Volumen 24. Springer - Verlag Berlin. 283 P.

Guraya S. 1989 b. Follicular atresia. Pp. 201-270. In W.Burggren, S.Ishii, H.Langer, G.Neuweiler and D.J. Randall (eds.) Ovarian Follicles in Reptiles and Birds. Zoophysiology. Vol. 24. Springer - Berlin Heildelberg.New York, London, Paris, Tokio.
InfoStat. 2002. Software Estadística, versión 2.0. Manual del Usuario, p. 92 -93. En Editorial Brujas Argentina. Grupo InfoStat. FCA, Universidad Nacional de Córdoba.

Ito K., Y. Kubokura, K. Kaneko, et al. 1988. Occurrence of Campylobacter jejuni in free-living birds from Japon. W.Wildlife Disease 24 (3): 467 -470.

Kovács, J., V. Forgó \& P. Péczely. 1992.The fine structure of the follicular cells in growing and atretic ovarian follicles of the domestic goose. Cell Tissue Res. 267: 561 - 589.

Lofts B., K. Murton \& N. Westwood. 1966. Gonadal cycles and the evolution of breeding seasons in British Columbiae. J. Zool., Lond. 150: 249-272.

Madekurozwa M. \& W. Kimaro. 2006. A morphological and inmunohistochemical study of healthy and atretic follicles in the ovary of the sexually inmature Ostrich (Struthio camelus). Anat. Histol.Embryiol. 35, 253-258.

Madekurozwa M. \& W. Kimaro. 2008. Ultrastructural features of atretic follicles in the sexually inmature Ostrich (Struthio camelus). 2008. Anat. Histol. Embryiol. 37, 309-313.

Maron C. 2007. Características estructurales y cuantitativas del ciclo reproductivo femenino en relación al régimen alimentario de Columba maculosa maculosa (Temminck, 1813) (Aves: Columbidae).Tesina de Grado. Inédito. Facultad de Ciencias Exactas,Físicas y Naturales. UNC.

Marrero P., P. Oliveira \& M. Nogales. 2004. Diet of the endemic Madeira Laurel pigeon and fruit resource avalilability: a study using microhistological analyses. The Condor 104 (4): $811-822$.

Nores M., D.Izurieta \& R.Miatello. 1983. Pp. 1-2. En: Lista y distribución de las aves de Córdoba,Argentina. En Bol. Ac.Nac. Cs.Córdoba Argentina, 56.

Pergolani de Costa M. 1961. La ornitología y los problemas agronómicos. Physis 22 (63):235-240.

Ribeiro M., M. Oliveira Teles \& S.Maruch. 1991. Aspectos morfológicos do ovário da rolinha Columbina talpacoti (Temminck, 1811), Columbidae, Columbiforme. Rev. Bras. Ciên. Morfol. 8 (2) jul./dez.

Ribeiro M., M.Oliveira Teles \& S. Maruch.1995. Morphological aspects of the ovary of Columba livia (Gmelin) (Columbidae, Columbiformes). Revta bras. Zool. 12(1): 151-157.

Rivera-Milán F., C.Ruiz, J.Cruz, et al. 2003. Reproduction of plain pigeons (Columba inornata wetmorei) in east-central Puerto Rico. The Auk 120(2):466-480.

Romeis B. 1928. La coloración p. 39-184. En: Editorial Labor S.A. Guía Formulario de Técnicas Histológicas. Barcelona Madrid- Buenos Aires.

Saini H \& H.Toor. 1991. Feeding ecology and damage potential of feral pigeons, Columba livia, in an agricultural habitar. Le Gerfaut 81: 195-206.

Wight H.M. 1959. A field technique for bursal inspection or mourning doves. J.Wildl.Mgmt. 20 (1):94 -95.

Yap C.\& N. Sodhi. 2004. Southeast Asian invasive birds: ecology, impact and management. Ornithol Sci 3:57-67.

Zarnescu O. 2004. Ultrastructural observations of previtelogenic ovarian follicle of dove. Zygote,12 (4): 285-92. 
